\title{
METAMORFOSES DO PENSAMENTO LIBERAL DE RUI BARBOSA: SUA POSIÇÃO SOBRE ESTADO E EDUCAÇÃO
}

\section{Metamorfoses do pensamento liberal de Rui Barbosa: sua posição sobre Estado e Educação}

\section{Resumo}

Maria Cristina Gomes Machado ${ }^{1}$ José Carlo de Souza Araújo ${ }^{2}$

Este artigo analisa as manifestações e apropriações do liberalismo por Rui Barbosa (1848 - 1923), no Brasil, no final do século XIX, explicitando as mudanças que se observam na concepção de Estado e educação desse autor. Suas posições foram expostas em artigos de jomais, em programas de govemo, em discursos na Câmara dos Deputados, em projetos de reforma, principalmente, no projeto de Reforma eleitoral de 1881 e no Projeto/parecer sobre a educação primária, secundánia e superior (1882 e 1883). Nestes pareceres defendeu a necessidade do Estado assumir total responsabilidade para com a oferta da educação desde 0 jardim de infância até o ensino superior, buscando garantiro acesso das camadas populares. Rui Barbosa foi um dos defensores dos postulados básicos do liberalismo, tendo participado por quase duas décadas como membro do Partido Liberal, entretanto, apropriou-se dessas idéias dando-lhes tonalidade própria, conforme a necessidade do país, e defendeu, no peńodo republicano, a interferência do Estado na economia, adotando medidas protecionistas à indústria nacional. Sua posição neste cargo assemelha-se a assumida quando da defesa da escola pública sob responsabilidade do Estado, demonstrando mudanças na sua concepção anterior no qual defendia a propriedade privada, a liberdade comercial, a liberdade de culto, a liberdade individual e a soberania do indivíduo. Rui Barbosa foi um ardoroso lutador, na luta pela modemização do Brasil combateu em várias frentes, a leitura do conjunto de sua obra revela as metamorfoses do pensamento desse autor.

Palavras-chave: Pensamento pedagógico de Rui Barbosa; Estado e educação; Pensamento liberal.

1 Doutora em Educação, Universidade Estadual de Maringá, Centro de Ciências Humanas, Letras e Artes, Departamento de Fundamentos da Educação - Av. Colombo, 5790, Zona 07, CEP: 87020-900, Maringá/PR

E-mail: crismach@mgalink.com.br

2 Doutor em Educação, professor do Programa de Pós-Graduação do Centro Universitário Triângulo. Av. Nicomedes Alves dos Santos, 4545, Gávea, Uberlândia/MG, CEP: 38411-106 e-mail: jcaraujo@unitri.edu.br 


\section{Abstrct}

Signs and appropriations of liberalism by Rui Barbosa (1848-1923) in Brazil at the end of the $19^{\text {th }}$ century are analyzed, while changes on his ideas of the State and on Education are explained. The statesman's stances were published in newspapers, in government programs, in Parliamentary speeches, in reform plans and mainly in the 1881 Election Reform Act and the 1882 and 1883 Act on Primary, Secondary and Higher Education. In his written speeches he defended the need of the State to take up total responsibility in schooling from the kindergarten to the College stage, in the course of which education access for the lower classes would be guaranteed. Rui Barbosa was one of the defenders of liberalism's basic suppositions since he had been a member of the Liberal party for almost two decades. Further, whereas he appropriated these ideas and gave them a twist of his own according to the country's needs, he defended state interference on the economy during the republican period and took protecting measures for Brazilian incipient industry. In his political role his stance was similar to that taken on his defense of the public school under the aegis of the State. Changes may thus be detected when contrasted to his previous ideas on private property, commercial, religious and individual freedom and the sovereignty of the individual person. Rui Barbosa, a zealous politician, struggled for the modemization of Brazil at several levels. The metamorphoses of his ideas may be revealed through the reading of his works.

Keywords: Pedagogical ideas of Rui Barbosa; State and education; liberal thought.

Este trabalho tem como objetivo analisar as manifestações e apropriações do liberalismo por Rui Barbosa (1848-1923), no Brasil, no final do século XIX, explicitando as mudanças que se observam na sua concepção de Estado e educação. Valdemarin (2000, p. 26) explicita que:

o adjetivo mais utilizado para definir Rui Barbosa é o de liberal. Termo este, utilizado de forma abrangente, ora refere-se ao fato de ser membro do Partido Liberal, ora ao fato de ser um defensor de idéias anacrônicas, ora, ainda, refere-se ao fato de ser um jurista que pautou sua ação na defesa das liberdades burguesas.

Suas posições foram expostas em artigos de jornais, em programas de governo, em discursos na Câmara dos Deputados, em projetos de reforma, principalmente, no projeto de Reforma eleitoral de 1881 e no projeto/parecer sobre a educação primária, secundária e superior (1882 e 1883). Sobre este, Rui Barbosa elaborou dois importantes diagnósticos sobre educação que se intitulam a "Reforma do Ensino Secundário e Superior" (1942) e a "Reforma do 
Ensino Primário e várias Instituições Complementares da Instrução Pública” (1947).

Nestes pareceres defendeu a necessidade do Estado assumir total responsabilidade para com a oferta da educação desde o jardim de infância até o ensino superior, buscando garantir o acesso das camadas populares. Para a universalização do ensino defendeu a gratuidade, a laicidade do ensino e a sua obrigatoriedade, mesmo que isso contrariasse a soberania e a liberdade individual do cidadão brasileiro. Esta sua posição mostrava-se diferente de sua defesa da liberdade individual, da liberdade de comércio e da sua compreensão do papel do Estado na sociedade, bem como de suas idéias defendidas como membro do Partido Liberal. Para Chacon, citado por Nabuco de Araújo (1979)

os anos de 1868 e 1869 foram decisivos para o liberalismo brasileiro ao registrar um momento de afirmação nacional. O gabinete liberal de Zacarias de Góis e Vasconcelos deixa a Presidência do Ministério e foi substituído por um membro do Partido Conservador, o Visconde de Itaboraí. Esse fato levou ao ostracismo do Partido Liberal que só retornaria ao poder em 1878, marcando também a ascensão desse partido, pois reunidos em torno do Centro Liberal, presidido por Nabuco de Araújo redigiram um Manifesto do Centro Liberal e deixaram claro seu programa de governo (Araújo, 1979, p. 106): 1. Reforma eleitoral; 2. Reforma policial e judiciária; 3. Abolição do recrutamento; 4. Abolição da Guarda Nacional; 5. Emancipação dos escravos. Rui Barbosa defendeu arduamente este programa na Câmara dos Deputados e pela imprensa. Sobre os programas dos Partidos no segundo Império recomenda-se a leitura de Brasiliense (1979).

\section{A Participação de Rui Barbosa na Política Brasileira: Suas Relações com o Liberalismo}

Rui Barbosa teve uma longa participação na vida política brasileira. Iniciou sua carreira como Deputado Provincial em sua cidade natal - Salvador, em 1878, como membro do Partido Liberal, permaneceu neste partido até 1886 quando discordou de algumas propostas encaminhadas, como a questão da Federação, simpatizando-se posteriormente com o Partido Republicano.

Para compreender o pensamento deste autor, exige-se que se examine a trajetória do liberalismo no final do Império e no período da Primeira República no Brasil, assumindo seu pensamento como um baluarte norteador dos encaminhamentos políticos e jurídicos. Nascido nos meados do século XIX, com 41 anos já se tomara Ministro da Fazenda do governo republicano 
instaurado em 15 de novembro de $1889^{3}$. Embora já tivesse inserção na vida política baiana como jornalista e defensor do Partido Liberal a partir de 1877 e logo a seguir na Câmara Provincial e depois na Câmara dos Deputados, seu ideário se assentou no republicanismo brasileiro expresso a partir do Manifesto de 1870. Sua trajetória biográfica se projetou até 1923, ano de sua morte (Fundação Casa de Rui Barbosa, 1995). Em síntese, sua inserção política de caráter liberal ocupou basicamente a Primeira República, além dos anos de embates no final do período imperial, contemplando este com olhares liberais ${ }^{4}$. Rodrigues (1982, p. 104) assim escreveu sobre este período:

No decorrer do Segundo Reinado, à margem dos estadistas do Império [...] formou-se uma nova geração liberal, menos realista e mais retórica, aberta aos influxos do liberalismo francês, às teses do positivismo 'liberal' de John Stuart Mill (1806-1873), à crítica às instituições tradicionais, inspirada no liberalismo radical de Thomas Paine e na tradição portuguesa de menosprezo pela monarquia, ensejada pelas Conferências do Casino (1871), sensível também aos temas do liberalismo norte-americano e conhecedora, de outro lado, das fontes do direito romano e do direito canônico, que continuavam sendo ensinados nas Escolas de Direito de Recife e de São Paulo. Essa nova geração constituiu, ao nosso ver, a tendência político-intelectual que foi denominada de "bacharelismo liberal".

Rui Barbosa foi participante da constituição desse bacharelismo liberal, sustentando os vínculos entre a sociedade e o Estado, afirmando a primeira como soberana na configuração do Estado, o qual deve servir a mesma sociedade. Essa tradição inglesa, que também estrutura a vivência liberal norte-americana, servirá de parâmetro a Rui Barbosa:

Foi grande, sem dúvida nenhuma, a contribuição de Rui Barbosa ao divulgar no Brasil as idéias básicas do liberalismo norte-americano. [...] Identificado com a tradição liberal anglo-saxônica, o ilustre baiano considerava que 0 Estado deveria estar a serviço da sociedade e, portanto, devia ser por ela controlado (RODRIGUES, 1982, p. 107).

Embora, ele tenha se tornado conhecido pela defesa da sociedade americana, é inegável a influência exercida pelo pensamento liberal inglês. Considerava a história inglesa importante por ser uma escola sobre o regime

3 Recomenda-se a leitura de Alves Filho "Brasil, 500 anos em Documentos" (1999, p. 283-296), para se conhecer os documentos emitidos pelo novo governo e uma minuciosa bibliografia sobre este tema.

4 Sobre a evolução do pensamento político de Rui Barbosa sugere-se a leitura de Barreto e Paim (1982). 
parlamentar. Entretanto, sua admiração pelos Estados Unidos se ampliou com o estabelecimento de vínculos com o ideário republicano, federalista e liberal que compuseram sua trajetória política, apesar de sua oscilação pendular, de um liberalismo que desamarrasse as peias constituídas pelo regime imperial, para um liberalismo que defendesse a ação interferente do Estado (REIS, 1918 citado por PAIM, 1981).

A crise do capitalismo na segunda metade do século XIX colocou em cheque o pensamento liberal clássico que alimentou a ascensão do capitalismo garantindo a supremacia da classe burguesa. A classe proletária organizou-se pressionando a burguesia, esta na defesa de seus interesses buscou apoio no Estado que passava a adotar uma política intervencionista no sentido de regulamentar o capital e o trabalho. No Brasil, também cresceram os discursos clamando para a adoção de uma nova direção do Estado. Como exemplo, podem-se citar os escritos de Aarão Reis nas primeiras décadas do século XX. Este autor fez crítica à economia política liberal e formulou uma doutrina centrada no intervencionismo estatal na economia, este, para ele, era decorrência do desenvolvimento da sociedade industrial (REIS, 1918 citado por PAIM, 1981).

Segundo Saldanha (1979, p. 173), Rui Barbosa situava-se na posição dos espíritos práticos e reflexivos, armados da força criadora do liberalismo progressista, "[...] mas possuídos também de reconhecimento para com o passado e inteligente confiança nas tendências esclarecidamente conservadoras da tradição, da inalterável fé nas crenças seculares do gênero humano depuradas pela filosofia e pela caridade [...]." Observe-se que tal posição acaba tornando eclética a afirmação de um liberalismo progressista, que assumiu a tradição, mas também o papel da filosofia e da caridade na configuração da humanidade. Tal posicionamento liberal esteve presente na introdução ao livro O Papa e o Concílio escrito por Barbosa em 1978, v. 4, t. 1 e 2, traduzido por Rui Barbosa e publicada, no Brasil, em 1877, ele expressou um norteamento que visava, mais do que justapor posições, afirmá-las como conviventes, lembrando inclusive a posição de Turgot em "Discursos sobre o progresso humano" de 1750, quando este argumentava sobre o papel da religião cristã na configuração do gênero humano e em seu progresso.

Tal questão pode permitir que se indague se o liberalismo de Rui Barbosa ou mesmo de outros seja um transplante do europeu, ou se resultou de uma concepção contextualizada, ainda que sob a influência dos norteamentos europeu e norte-americano. Na verdade, como a inserção brasileira no que se denominou por modernidade veio se fazendo inclusive no período republicano, no qual se encerrou a trajetória de Rui Barbosa em busca de suas realizações norteadas pelo ideário liberal, é necessário compreender que a apropriação e a reapropriação do ideário político, bem como a sua veiculação interna ao país, passou por influências européias e norte-americanas. 
As posições de Rui Barbosa relativas ao papel do Estado, ao federalismo, ao presidencialismo, ao constitucionalismo, ao republicanismo não se fizeram desconhecedoras de tal apropriação; por outro lado, não se pode isentá-lo do esforço de compreender e de projetar um direcionamento político atento à dinâmica nacional e às contradições internas, bem como às determinações internacionais.

O posicionamento liberal brasileiro, portanto, enfrentou as peculiaridades intrínsecas ao processo histórico brasileiro: a posição de Rui Barbosa foi emblemática, pois tratou ela de fazer frente à monarquia, ao Poder Moderador, de defender o direito ao voto, bem como de defesa de uma concepção secular de Estado desvinculada dos laços com a Igreja Católica, de uma escola pública laica, de uma postura republicana e de uma organização federativa. 0 enfrentamento de Rui Barbosa se pautou pela construção de um edifício político que permitisse erguer-se para a constituição de um direcionamento liberal. É possível compreender seus arroubos iniciais assentados num liberalismo sem peias, que pusesse a sociedade e o Estado associados em torno de tal construção. Mas sua trajetória - a de quem buscou acompanhar o movimento da história brasileira, referente ao seu percurso como homem público - explicitou um liberalismo que concebeu a necessidade da interferência do Estado nos destinos do país. Afinal, sua trajetória como escritor - e que traduz o seu percurso pendular para um liberalismo mais interveniente - explicita o quanto ele veio se tornando o diapasão que permitiu afinar a explicitação liberal no período da Primeira República.

\section{As Idéias de Rui Barbosa: 0 Papel do Estado e da Educação}

Os primeiros escritos como jornalista ou parlamentar de Rui Barbosa apresentaram suas idéias acerca da liberdade comercial e do papel do Estado. Todo o Nordeste, no ano de 1878, sofreu as conseqüências de uma seca que durou em torno de três anos (1877-79), a Bahia continuou produzindo a farinha de mandioca, alimento principal da população. Porém, o preço subiu demasiadamente e a província baiana passou a vender a farinha por um preço maior às outras províncias. O governo, para evitar calamidade pública e fome, apresentou um projeto à Câmara proibindo a exportação do produto. Os oposicionistas do governo alegaram que essa medida estava em contradição com as convicções liberais, tornando-se um atentado contra a liberdade comercial. Rui Barbosa fez a defesa contra tais acusações, recorrendo a Adam Smith, este embora fosse liberal defendia os subsídios ao trigo para alimentar os trabalhadores. Permitia-se assim, exceções, esta sua atitude justificaria medidas como a tomada pelo governo baiano (BARBOSA, 1983, v.5, t.1, p.29). Entretanto, no 
Metamorfoses do pensamento liberal de Rui Barbosa: sua posição sobre Estado e Educação

mesmo discurso, defendia a soberania do indivíduo, apresentando arduamente os princípios liberais:

Tão íntima, tão ilimitada, tão inauferivelmente pertencem ao indivíduo a sua ação como as suas forças, a sua indústria como a sua ação, as suas obras como a sua indústria. Dispor automaticamente das criações do seu gênio, da sua vocação, da sua ciência, da sua aplicação laboriosa, consumi-las, permutá-las, negociá-las, onde, quando, como convenha ao interesse do produtor, essa uma das fundamentais necessidades humanas, necessidade que, felizmente, está à sombra, não só do princípio individualista, como do interesse social (BARBOSA, 1983, v. 5, t. 1, p. 42).

Com esse raciocínio mostrou que impor taxas ou preço ao mercado era atentar contra a liberdade. Não se podia considerar povo e Estado como duas entidades de existência independentes, em outras palavras, considerava que não era o Estado quem fazia os cidadãos, mas os cidadãos que faziam 0 Estado. Assim, definiu o Estado:

Sem religião, sem moral, pelo menos, sem educação, sem indústria, sem comércio, o Estado não subsiste; porque falta-lhe meio, falta-lhe o ambiente, falta-lhe o objeto de suas funções, que é estabelecer derredor de tudo isso uma atmosfera de segurança, de justiça, de paz, onde a satisfação de todas essas necessidades humanas, onde todas essas manifestações de humana atividade girem e se desenvolvam livremente. Mas o que não é condição de vida para o Estado, nem de estabilidade para a ordem, é o protecionismo comencial, a nacionalização artificial da indústria, uma moral privilegiada, uma religião monopolista. Infiltrando no povo essas noções sólidas, educando-o assim, demos-lhe a grande, a simples, a genuína intuição, a intuição liberal do papel do Estado nos govemos modemos, do seu ideal (BARBOSA, 1983, v. 5, t. I, p. 46-7)

Retomou as antigas lutas do Partido Liberal que ainda não haviam sido esquecidas, como a moralização do orçamento e a eleição direta. Sobre esta questão escreveu que ela não era tão simples como parecia, mas era complexa. Todas as outras reformas eram conseqüências dessa. Essas outras reformas eram; "abolição da Guarda Nacional, recrutamento exclusivamente voluntário da força armada, reforma policial, reforma judiciária, tudo isso rodeando, sustentando, inteirando a reforma eleitoral, base, eixo e cúpula do programa" (BARBOSA, 1983, v. 5, t. 1, p. 62).

O projeto sobre eleição foi levado à Câmara pelo ministro do Império, barão Homem de Melo, tendo sido elaborado por Rui Barbosa a pedido de José Antônio Saraiva. Este redigiu as bases do projeto cuja redação foi feita por Rui Barbosa. No discurso feito pode-se destacar sua compreensão sobre 0 sistema representativo: 
A base do nosso regime, a sua única base é a democracia. Na administração dos nossos interesses políticos, a soberania do povo é o alfa e o ômega, o princípio e o fim. Nenhuma autoridade, seja qual for, coparticipa com ela nesta supremacia, cuja expressão ideal não tem limites senão, de uma parte, o direito individual reconhecido por ela mesma, de outra o princípio da própria conservação, a irrenunciabilidade do seu poder; nesta supremacia, cuja onipotência só conhece duas impossibilidades jurídicas, não propriamente limitações da sua esfera, mas sublimidades de sua natureza - a de compor-se de individualidades mutiladas, opressas, e a desistir da sua existência suprema: o suicídio pela supressão da liberdade civil sob organizações socialista, e o suicídio por abdicação em favor de uma oligarquia ou de um autócrata; a supressão de si próprio pela servidão política ou civil. Nas nossas instituições orgânicas, portanto, só o elemento popular é eterno, substancial, imutável (BARBOSA, 1945, v. 7, t. 1, p.11)

Para ele, tanto a monarquia como a república, que elegia temporariamente seus representantes, tinham o sistema representativo como sagrado. Este só era possível quando a eleição direta fosse uma "realidade perfeita". No Brasil, o sistema de eleição deixava ao arbítrio de um e outro verificar o direito de voto, muitas vezes aqueles que tinham o direito de voto eram impedidos de votar, votando quem não o poderia fazer de acordo com Barbosa (1945, v. 7, t. 1, p. 16), a mercê de interesses alheios o indivíduo perdia seu direito de voto. No novo sistema só votariam aqueles que provassem estar aptos conforme a lei, estabelecendo renda mínima e necessidade de escolarização, concedendo o direito ao título vitalício de eleitor. Assim, o projeto visava a exterminação da fraude que eliminou o governo e a democracia. O projeto impedia 0 voto do analfabeto, Rui Barbosa afirmava não o excluir à medida que eles deveriam ser educados para usufruírem de seus direitos. Em outros países era por meio da educação que os analfabetos se aproximavam do governo (BARBOSA, 1945, v. 7, t. 1, p.30). Neste projeto se incluiu a elegibilidades dos não católicos e dos libertos. A vitaliciedade do título garantiria um eleitorado independente e estável. Entretanto, este projeto foi muito criticado, frente aos comentários de que o país não queria a reforma, Rui Barbosa recorreu às palavras do barão de Rio Branco apud (BARBOSA, 1945, v. 7, t. 1, p. 66):

Apesar de nunca ter sido pessimista" [...] "não encaro tranqüilamente as circunstâncias do Império; a lavoura clama por braços, capitais e instrução; a indústria pede a liberdade de associação, garantia de direitos e finanças; a população em geral geme carregada de tributos, submetida a sacrifícios que só a guerra explicava; não há segurança para o indivíduo, nem para a propriedade. 
Desta forma, Rui Barbosa defendia segurança do indivíduo e a sua propriedade. Estes não poderiam sofrer nenhum tipo de embaraço, nem mesmo da Igreja Católica que estava atrelada ao Estado brasileiro. Neste sentido, denunciava a incompatibilidade dos liberais com a religião de Estado. A Igreja Católica não podia reconciliar-se com o progresso, com o liberalismo e com a civilização moderna. Liberdade e ciência, ao contrário, andavam juntas.

Embora como Ministro da Fazenda do Governo Provisório em 1889 tenha adotado medidas econômicas que protegessem e fomentassem o desenvolvimento da indústria nacional, anteriormente havia se mostrado contrário à interferência do Estado na economia. Fez um discurso, em 1880, em defesa da liberdade comercial, mostrando-se contrário à concessão de privilégio para a fabricação do sulfureto de carbono, e se expressando da seguinte forma:

Não pertencendo à escola disposta a proteger a indústria nacional, o trabalho nacional à custa da liberdade do trabalho, à custa da liberdade de indústria, declaro-me intransigentemente hostil a toda espécie de medidas tendentes a assegurar à indústria, ao trabalho, outra proteção que não seja a da liberdade, a do direito comum, a única proveitosa, a única legítima, a única razoável, a com que exclusivamente deve contar o trabalho nacional (BARBOSA, 1945, v. 7, t. 1, p. 224-5).

Ao analisar as conseqüências de medidas protetoras, Rui Barbosa descreveu a situação da agricultura: "São ainda rudimentares entre nós os métodos de amanhar a terra; exaurem-na continuamente sem ressarcir-lhe, por meio de um cultivo restaurador, as substâncias nutritivas absorvidas sucessivamente pelas colheitas" (BARBOSA, 1945, v.7, t. 1, p.238-9). Para superar esse quadro, a educação cumpriria um duplo papel: anunciou-se acima a sua importância para preparar o indivíduo para o exercício da cidadania, aqui aparece outra tarefa fundamental, que é preparar o homem para o trabalho agrícola, como no exemplo anterior, ou para a indústria. $\mathrm{O}$ ensino da ciência poderia modernizar a forma rudimentar pela qual o trabalho estava sendo desenvolvido (MACHADO, 2002). O Estado deveria ofertar uma educação gratuita, pois ela, se deixada à livre concorrência do mercado, se desenvolveria de forma muito lenta.

Os pareceres de Rui Barbosa constituíram-se em um inquérito sobre o ensino da época. Eles inovaram os tratados de educação do período. Tudo era diferente: a vastidão com a qual os assuntos foram abordados, a quantidade de documentos referentes à educação no Brasil e fora dele, a argumentação bem elaborada além de utilizar-se da exposição de números, relatos de congressos, entrevistas de professores e a história de algumas instituições escolares. A partir de seus estudos defendeu a necessidade de organização de um sistema nacional de ensino. Este sistema deveria ser mantido e administra- 
do pelo Estado, somente ele poderia conferir graus. A educação não podia ser tratada pelas leis econômicas de oferta e procura, pois era um empreendimento caro e complexo que daria resultados apenas a longo prazo, assim a liberdade de ensino só traria vantagens, no Brasil, para a Igreja Católica. Esta era a única que estava preparada para ofertar o ensino. Sobre a liberdade de ensino escreveu:

Em suma, só almejo a liberdade de ensino, até onde chegar a liberdade, franqueada a todas as crenças, de se manifestarem, a todos os partidos, de fundarem escolas, e não como abstenção completa do Estado em todas as questões que toquem ao domínio da instrução geral. O ensino oficial não deve embaraçar o ensino livre; mas, por enquanto, o ensino livre não poderia suprir a falta do ensino oficial (BARBOSA, 1947, v. 10, t. 1, p. 97).

Citou exemplos de países eminentemente individualistas que adotavam o ensino oficial: Inglaterra, Estados Unidos e Suíça. Considerava que a educação era uma das coisas "que, podemo-lo admitir como princípio, o governo deve distribuir ao povo. Ela constitui um dos casos a que não se aplicam necessariamente os motivos da regra da não intervenção, e a quem nem todos esses motivos são aplicados” (BARBOSA, 1947, v. 10, t. 1, p. 107). Rui Barbosa sobre esta questão escreveu que alguns teóricos reprovam:

[...] o progressivo alargamento da ação protetora e tranqüilizadora do Estado nesta esfera, - a tendência universal dos fatos, na mais perfeita antítese com essas pretensões, com o subjetivismo das teorias dessa nova classe de doutrinánios, reforça, e amplia, entre os povos mais individualistas, com 0 assentimento caloroso dos publicistas mais liberais, o círculo das instituições ensinantes alimentadas pelo erário geral; aduz todo dia o concurso de novos argumentos em apoio da colação dos títulos universitários sob a garantia do Estado, e reconhece, cada vez com mais força, a necessidade crescente de uma organização nacional do ensino, desde a escola até às faculdades, profusamente dotada nos orçamentos e adaptada a todos os gêneros de cultivo da inteligência humana (BARBOSA, 1947, v. 10 t. 1, p. 85-86).

\section{Considerações Finais}

Nos primeiros escritos, ele declarou-se um admirador do liberalismo à forma inglesa e mostrou-se um ardoroso defensor do programa do Partido Liberal brasileiro. Este, entre outras questões, buscava reformar a instrução pública, transformar o trabalho servil em trabalho livre, adotar papel-moeda, fazer a reforma do judiciário e reorganizar os municípios. Ele defendeu a 
propriedade privada, a liberdade comercial, a liberdade de culto, a liberdade individual, a soberania do indivíduo, aproximando-se do liberalismo. Embora seja difícil defini-lo ao longo dos tempos, este surgiu como uma corrente teórica que sustentou a prática burguesa que se desenvolveu no momento de transição da sociedade feudal para a sociedade capitalista, justificando assim a nova forma social. Seu ideário cruzou o Atlântico e influenciou os pensadores no Brasil.

Rui Barbosa foi um dos defensores de seus postulados básicos, entretanto deu ao liberalismo uma tonalidade própria, conforme a necessidade do país, e defendeu, quando Ministro da Fazendo do Governo Provisório de Deodoro da Fonseca, em 1889, a interferência do Estado na economia, adotando medidas protecionistas à indústria nacional. Sua posição neste cargo assemelha-se a assumida quando da defesa da escola pública sob a responsabilidade do Estado, demonstrando mudanças na sua concepção anterior. Ele era um ardoroso lutador e estava sempre em combate, em cada um deles buscando resolver os conflitos estudando e buscando novas idéias. A sua luta em torno da modernização do Brasil fez com que combatesse em várias frentes, sendo que a leitura do conjunto de sua obra revela a metamorfose de seu pensamento, ou como se intitula um de seus discursos, "meu programa está na minha vida".

\section{Referências}

ALVESFILHO, I. Brasil, $\mathbf{5 0 0}$ anos em documentos. Rio de Janeiro, RJ: Mauad, 1999.

ARAÚJO, José Thomaz Nabuco de. O Centro Liberal. Brasília, DF: Senado Federal, 1979.

BARBOSA, R. Discursos na Assembléia Provincial da Bahia. Obras Completas. Rio de Janeiro, RJ: Fundação Casa de Rui Barbosa, 1983. v. 5, tomo. 1.

. Discursos Parlamentares (Câmara dos Deputados). Obras Completas. Rio de Janeiro, RJ: Ministério da Educação e Saúde, 1945. v. 6 e 7, tomo. 1.

.Reforma do ensino secundário e superior. Obras completas. Rio de Janeiro, RJ: Ministério da Educação e Saúde, 1942. v. 9, tomo 1.

. Reforma do ensino primário e várias instituições complementares da instrução pública. Obras completas. Rio de Janeiro, RJ: Ministério da Educação e Saúde, 1947. v. 10, tomo 1-4. 
. O Papa e o Concílio (Tradução). Obras Completas. Rio de Janeiro, RJ: Ministério da Educação e Saúde, 1978. v. 4, tomo 1 e 2.

BARRETO, V. PAIM, A. Liberalismo, autoritarismo e conservadorismo na República Velha. In: Curso de introdução ao pensamento político brasileiro. Brasília, DF: Editora Universidade de Brasília, 1982.

CHACON, V. Manifesto do Centro e Programa do Partido Liberal. In: ARAÚJO, José Thomaz Nabuco de. O Centro Liberal. Brasília, DF: Senado Federal, 1979.

FUNDAÇÃO CASA DE RUI BARBOSA. Rui Barbosa: cronologia da vida e obra. Rio de Janeiro, RJ: Fundação Casa de Rui Barbosa, 1995.

GONÇALVES, V. T. V. O liberalismo demiurgo: estudo sobre a reforma educacional projetada nos Pareceres de Rui Barbosa. São Paulo, SP: Cultura Acadêmica, 2000.

MACHADO, M. C. G. Rui Barbosa: pensamento e ação. Campinas: Autores Associados, 2002.

MELO, A. B. de A. Os programas dos partidos e o Segundo Império. Brasília,DF: Senado Federal, 1979.

REIS, A. O regime político e o papel do Estado. In: PAIM, A. (Org.). Plataforma política e positivismo ilustrado. Brasília, DF: Universidade de Brasília, 1981.

RODRIGUES, R. V. A propaganda republicana. Curso de introdução ao pensamento político brasileiro. Brasília, DF: Ed. UnB, 1982. (Apostila).

SALDANHA, N. Rui Barbosa e o bacharelismo liberal. In: CRIPPA, A. As idéias políticas no Brasil. São Paulo, SP: Convívio, 1979, v. 1.

Recebido em: 26/08/2004

Aprovado em: 30/11/2004 